\title{
Comparative Study of Pure Mg and AZ91D as Sacrificial Anodes for Reinforced Cement Concrete Structures in a Chloride Atmosphere
}

\author{
Yogesh I. Murthy ${ }^{a,{ }^{*}}$ Sumit Gandhi ${ }^{a}$ and Abhishek Kumar ${ }^{b}$ \\ ${ }^{a}$ Department of Chemical, Metallurgical and Materials Engineering, Tshwane \\ University of Technology, P.M.B. X680, Pretoria, South Africa \\ ${ }^{b}$ Department of Mechanical Engineering, Covenant University, P.M.B. 1023, \\ Canaan land, Ota, Nigeria
}

Received November 26, 2017; accepted June 8, 2018

\begin{abstract}
A comparative study of the corrosion behavior of pure magnesium and AZ91D anodes in reinforced cement concrete was undertaken in the present work. The steel reinforcements were electrochemically kept in contact with these anodes in a chloride atmosphere, and the half-cell potential drop was observed. Bare steel reinforcements were tied to the anodes and were also kept in a high chloride atmosphere to test the mechanical properties. The yield stress and ultimate tensile stress were found to decrease by approximately $50 \mathrm{MPa}$, while the reduction in percentage elongation was approximately $25 \%$ for reinforcements tied to AZ91D and pure $\mathrm{Mg}$, at the end of 80 days, compared to the fresh steel reinforcement. The rate of corrosion of pure $\mathrm{Mg}$ was reportedly slightly higher compared to AZ91D, due to the presence of inter-metallics, as inferred through micro-graphs.
\end{abstract}

Keywords: cathodic protection, AZ91D, mechanical properties, half-cell potential, micro-characterization, inter-metallics.

\section{Introduction}

Cathodic protection (CP) of reinforced cement concrete (RCC) structures has been in practice since decades. This technique is widely used for structural integrity against corrosion in regions exposed to a chloride atmosphere or extreme marine environments [4,6]. The underlying principle of CP technique is based on an electro-chemical reaction involving the anodic dissolution of metal by providing electrons to the metal structure protection. The process of $\mathrm{CP}$ can be accomplished in two ways, viz. impressed current cathodic protection (ICCP) and galvanic coupling or sacrificial anoding of a suitable material. The most commonly used anode amongst the latter technique is pure magnesium $(\mathrm{NMg})$

\footnotetext{
*Corresponding author. E-mail address: yogesh.murthy@juet.ac.in
} 
[3]. Its low efficiency $(\sim 50 \%)$ is surpassed by the very high negative potential, which in turn provides high current output. The corrosion rate of $\mathrm{Mg}$ is high, and hence, alloying is pursued. Amongst the alloys of $\mathrm{Mg}, \mathrm{AZ91D}$ is a very commonly used alloy for CP. Although significant research could be found on the use of $\mathrm{Mg}$ and AZ91D for $\mathrm{CP}$, there is very little work on the mechanical behavior of steel protected with these anodes and on the micro-structural characterization of such anodes [1-2,8]. Additionally, not much work is reported on the systematic experimental investigation of macro-cell corrosion of these anodes $[1,4]$.

Thus, the primary focus of the current research is to compare the ability of pure $\mathrm{Mg}$ and AZ91D in the corrosion mitigation in RCC, study the mechanical behavior of bare steel reinforcements tied with the anodes in a high chloride atmosphere, and microscopically examining the corroded anodes. A systematic analysis of the corrosion behavior of the anodes is expected to aid in the selection of suitable anodes under different conditions.

\section{Experimental set-up}

The experiment was performed in two stages. Pure Mg and AZ91D anodes were first embedded in a reinforced concrete slab, and half-cell potential was measured for 270 days. Next, bare steel reinforcements were fastened with anodes and placed in a high chloride atmosphere for 80 days. The detailed experimental set-up is discussed below.

\section{Reinforced concrete slab}

Four reinforced cement concrete slabs of dimensions $1000 \mathrm{~mm}$ x $1000 \mathrm{~mm} \times 100$ mm were cast using 1:1.5:3 nominal mixes and a water to cement ratio of 0.45 . All the slabs used $10 \mathrm{~mm}$ diameter steel reinforcements mats placed with a clear cover of $25 \mathrm{~mm}$ from all sides and with a center spacing of $190 \mathrm{~mm}$, as shown in Fig.1.

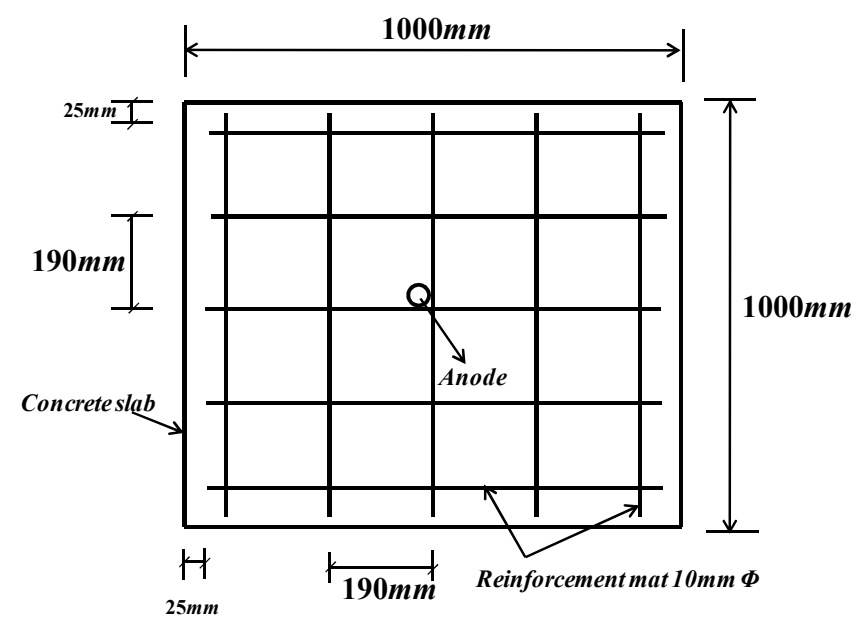

Figure 1. Detailing of reinforcement spacing and position of anodes for all four slabs. 
The surface area of the steel reinforcement mat was found to be $1.884 \mathrm{~m}^{2}$. The reinforcements were treated with a pickling solution, in order to remove corrosion sites. Anodes with $22 \mathrm{~mm}$ diameter and $250 \mathrm{~mm}$ long were centrally placed and tied intact to complete the electrochemical cell. Slab one and two were casted without $\mathrm{NaCl}$ and with $3.5 \% \mathrm{NaCl}$ by weight of cement, respectively, using pure as cast $\mathrm{Mg}$ anodes. Similarly, slab three and four were cast without $\mathrm{NaCl}$ and with $3.5 \% \mathrm{NaCl}$ by weight of cement using, as cast, AZ91D anode, respectively. The notations for all the slabs are shown in Table 1. These slabs were constructed using tap water with specifications, as shown in Table 2, on the same day, so as to maintain similar casting conditions.

Table 1. Notation of different cases of cathodic protection

\begin{tabular}{cll}
\hline S.No. & \multicolumn{1}{c}{ Description } & Notation \\
\hline $\mathbf{1}$ & Without $\mathrm{NaCl}$ with pure $\mathrm{Mg}$ anode & CP0M \\
$\mathbf{2}$ & With $3.5 \% \mathrm{NaCl}$ by weight of cement with pure $\mathrm{Mg}$ anode & CP35M \\
$\mathbf{3}$ & Without $\mathrm{NaCl}$ with AZ91D anode & CP0AZ91D \\
$\mathbf{4}$ & With 3.5\% NaCl by weight of cement with Az91D anode & CP35AZ91D \\
\hline
\end{tabular}

The test for tap water was conducted strictly in accordance to IS: 10500:2012 [7]. Bureau of Indian Standards), and it was observed that the tap water consisted of $0.1 \mathrm{mg} / \mathrm{L}$ of free residual chlorine and $0.4 \mathrm{mg} / \mathrm{L}$ of fluoride ions. These free ions contribute to the conductivity of the electrolyte, viz. concrete, in this case. But, since all the slabs were cast with same free chloride and fluoride content, the effects of these ions are the same in all cases and, hence, innocuous.

Table 2. Tap water characteristics confirming IS: 10500:2012.

\begin{tabular}{lll}
\hline S No. & Parameter & Value \\
\hline 1 & Chloride & $168 \mathrm{mg} / \mathrm{L}$ \\
2 & $\mathrm{pH}$ & 7.6 \\
3 & Fluoride & $0.4 \mathrm{mg} / \mathrm{L}$ \\
4 & Dissolved oxygen & $10.15 \mathrm{mg} / \mathrm{L}$ \\
5 & Chemical oxygen demand & 0 \\
6 & Biological oxygen demand & 0 \\
7 & Free residual chlorine & $0.1 \mathrm{mg} / \mathrm{L}$ \\
\hline
\end{tabular}

\section{Test set-up for bare steel in a chloride atmosphere}

In order to further investigate the performance of pure $\mathrm{Mg}$ and AZ91D anodes on the corrosion prevention of bare steel reinforcements, three sets of six steel reinforcements were tied together intact, with a centrally placed anode to complete the electrochemical cell. All the samples were dipped in a high chloride atmosphere of $7.5 \% \mathrm{NaCl}$ in tap water. Sample set one did not contain any anode; sample set two consisted of a AZ91D anode, while sample set three contained a pure $\mathrm{Mg}$ anode. These samples were tested for weight loss, tensile strength and microstructure. The set-up consisted of a container $1 \mathrm{~m} \mathrm{x} 1 \mathrm{~m} \mathrm{x} 1 \mathrm{~m}$, as shown in Fig. 2. 


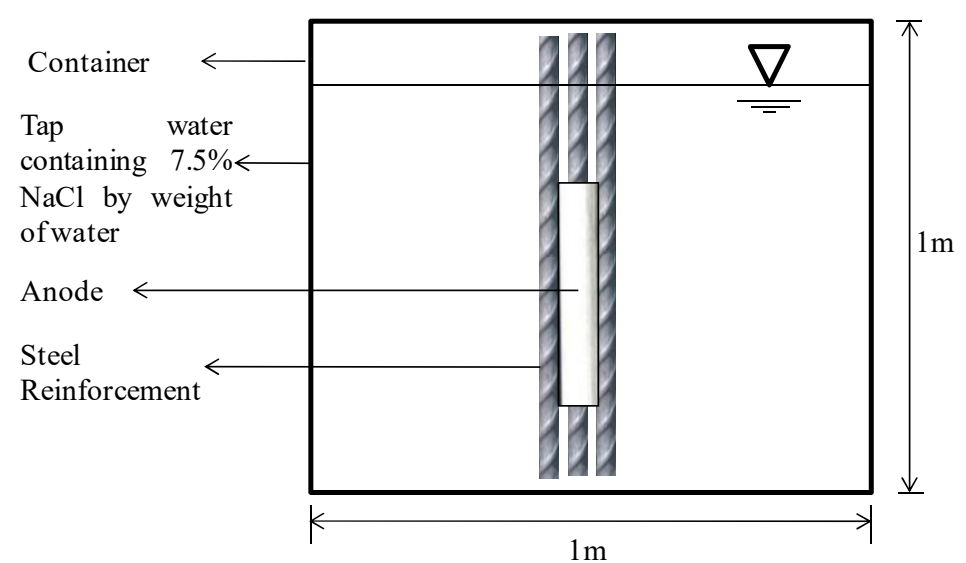

Figure 2. Schematic of set-up used to access the performance of anodes in a high $\mathrm{NaCl}$ content atmosphere.

The bare steel reinforcements were selected from the same lot of steel, so as to maintain a uniform chemical composition, and were treated with a pickling solution to remove initial corrosion sites. It was ensured that the samples were kept vertical and undisturbed in the container. All the readings were taken on the same days and at the same time, to nullify the effect of variations in relative humidity and temperature.

\section{Results and discussion}

Comparison of the potential of reinforcement embedded in concrete for a slab without anode, with a pure Mg anode and with AZ91D

Fig. 3 shows the variation of the negative potential of the concrete slab, with respect to Standard Calomel Electrode $(\mathrm{SCE})$, at a distance of $10 \mathrm{~cm}$ from the anode, for different days.

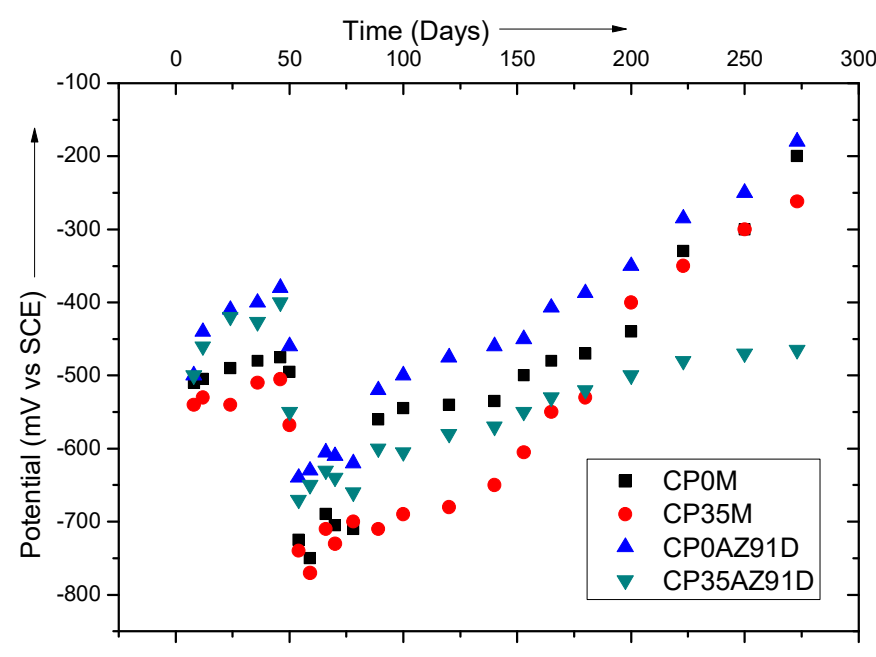

Figure 3. Variation of the negative potential of the slab w.r.t. SCE for various days, at a distance of $10 \mathrm{~cm}$ from anodes for all four cases.

In general, as expected, it could be found that, as the number of days increased, the negative potential w.r.t. SCE decreased. Another obvious result is that the slabs without $\mathrm{NaCl}$ had relatively less negative potentials. 
Further, among the two slabs without $\mathrm{NaCl}$, it was found that the cathodic protection of the slab containing AZ91D (i.e. CP35AZ91D) without $\mathrm{NaCl}$ had the least negative potential. This could be attributed to the fact that the interaction of $\mathrm{Al}, \mathrm{Mg}$ and $\mathrm{Zn}$ leads to the formation of various intermetallics, which have different electrochemical potentials, compared to pure Mg. Thus, the overall electrochemical potential of the alloy is lower, leading to a slower rate of corrosion.

Another interesting observation is the increasing trend of the negative potential during the $50^{\text {th }}$ to $100^{\text {th }}$ day. Since the slabs were exposed to atmosphere, the ingress of water during monsoon, led to an increased conductivity of the slab, leading to higher negative potential values.

The negative potential of the slab CP35M reduced drastically after nearly 175 days. This could be possible due to the rapid consumption of free chloride ions by pure $\mathrm{Mg}$, according to the following reaction:

$$
\mathrm{Mg}+2 \mathrm{Cl}^{-} \rightarrow \mathrm{MgCl}_{2}
$$

This notion is further augmented by the fact that, as the number of days increased, several radial cracks along with white crystalline deposits could be observed around the pure $\mathrm{Mg}$ anode, which is due to the increased volume of $\mathrm{MgCl}_{2}$. The chemical composition of the crystalline white deposits was analyzed, and it was confirmed that the deposits typically consisted of $\mathrm{MgCl}_{2}$ and $\mathrm{Cl}_{2}$, the latter being in very low quantity, probably deposited due to condensation.

It is also observed that, by the $270^{\text {th }}$ day, the negative potential of all slabs, except CP35AZ91D, were in the range of -200 to $-300 \mathrm{mV}$ w.r.t. SCE. Much higher negative potentials of the slab containing $3.5 \% \mathrm{NaCl}$ and $\mathrm{AZ91D}$ anode further augment the proposition of the formation of intermettalics and, hence, reduced rates of interaction with $\mathrm{Cl}^{-}$ions.

\section{Comparison of tensile strength in bare steel bars with AZ91D and pure Mg anode}

Three sets of six bare steel reinforcements, $950 \mathrm{~mm}$ long and with $10 \mathrm{~mm}$ diameter, were closely tied with centrally placed anodes, with $22 \mathrm{~mm}$ diameter and $250 \mathrm{~mm}$ long. The cross section for the set-up is as shown in Fig. 4. The steel reinforcements were maintained at a height of $200 \mathrm{~mm}$ from the bottom, in order to ensure partial immersion, and were kept undisturbed. The temperature of the set-up was maintained at $27^{\circ} \mathrm{C}$. Steel rods were taken out on the $20^{\text {th }}, 40^{\text {th }}, 60^{\text {th }}$ and $80^{\text {th }}$ days and tested for tensile strength in a 100 ton Universal Testing Machine for yield stress, ultimate stress and \% elongation. The results for the tensile test of AZ91D and pure Mg are presented in Fig. 5 (a and b), respectively. From Fig. 5 it could be inferred that, compared to the fresh steel reinforcement, in both the cases, there was a drop in the yield stress and ultimate tensile stress by nearly $50 \mathrm{MPa}$, at the end of 80 days.

The drop in percentage elongation for these reinforcements is shown in Fig. 6. At the end of the test period, it was found that this reduction in percentage elongation was approximately $25 \%$ for reinforcements tied to AZ91D and pure 
$\mathrm{Mg}$; however, the reduction in the case of AZ91D was observed to be slightly higher compared to pure $\mathrm{Mg}$ anodes.

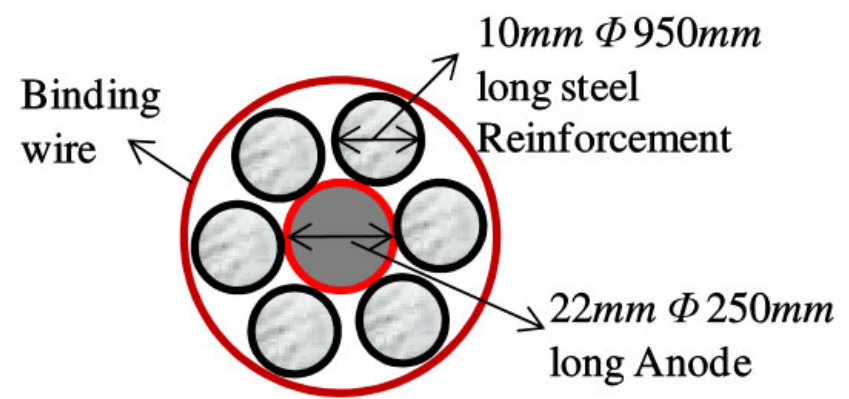

Figure 4. Cross-section of set-up for the test of bare steel reinforcement.
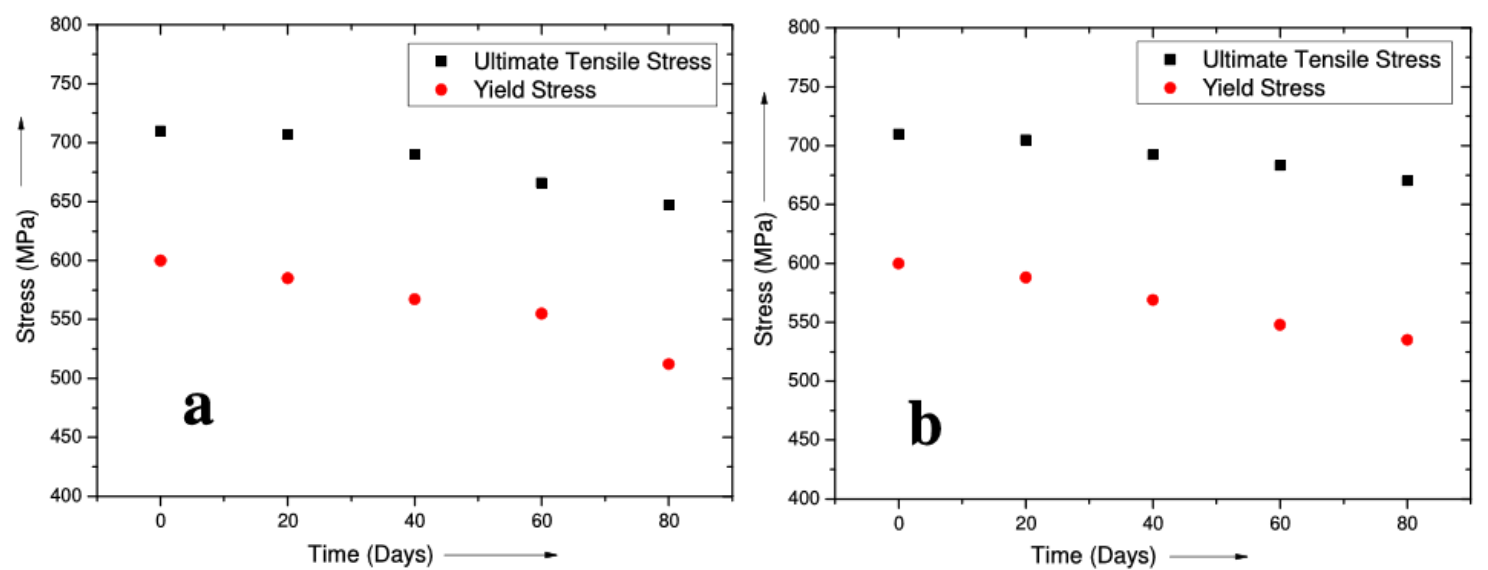

Figure 5. Yield stress and ultimate tensile stress of steel reinforcement in MPa under high chloride (7.5\%) atmosphere with (a) AZ91D and (b) pure Mg.

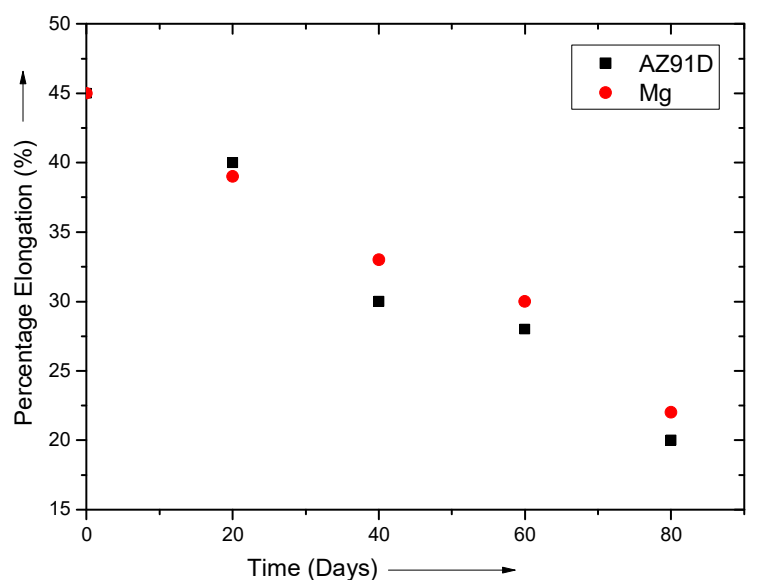

Figure 6. Percentage elongation of steel reinforcement under high chloride $(7.5 \%)$ atmosphere with AZ91D and pure Mg.

Comparison of the rate of corrosion in bare steel bars with AZ91D and with pure Mg anode

The rate of corrosion in both the cases was evaluated and is presented in Table 3 , using the standard expression, as mentioned below:

$$
\text { Rate of corrosion }(\mathrm{mm} / \mathrm{yr})=87.6 \times \frac{W}{D A T}
$$


where, $\mathrm{W}=$ weight loss in milligrams, $\mathrm{D}=$ density of steel (obtained as 7.89 $\mathrm{g} / \mathrm{cc}), \mathrm{A}=$ area of steel $\left(\mathrm{cm}^{2}\right)$ and $\mathrm{T}=$ time of exposure to chloride atmosphere in hours.

Table 3. Rate of corrosion ( $\mathrm{mm} / \mathrm{yr})$.

\begin{tabular}{cccc}
\hline S.No. & Time (Days) & Pure Mg & AZ91D \\
\hline 1 & 0 & 0 & 0 \\
2 & 20 & 0.127819 & 0.10091 \\
3 & 40 & 0.08981 & 0.077364 \\
4 & 60 & 0.069516 & 0.061667 \\
5 & 80 & 0.0555 & 0.052978 \\
\hline
\end{tabular}

One of the obvious results observed from Table 3 is that the rate of corrosion is faster at the beginning, and slower as the time proceeds. Also, the rate of corrosion of pure $\mathrm{Mg}$ is slightly higher compared to AZ91D.

\section{Microstructure of corroded anodes (Mg/ AZ91D) vs. un-corroded.}

The anodes from the concrete were taken after 270 days of embedment, and observed microscopically using Hitachi S-3400N SEM equipped with Energy Dispersive Spectroscopy (EDS). The analysis of the samples was carried out with a $2 \mu \mathrm{m}$ probe diameter, $10 \mathrm{kV}$ accelerating voltage and $50 \mathrm{nA}$ probe current. The error of the SEM measurements is estimated to be about \pm 2 at. $\%$.
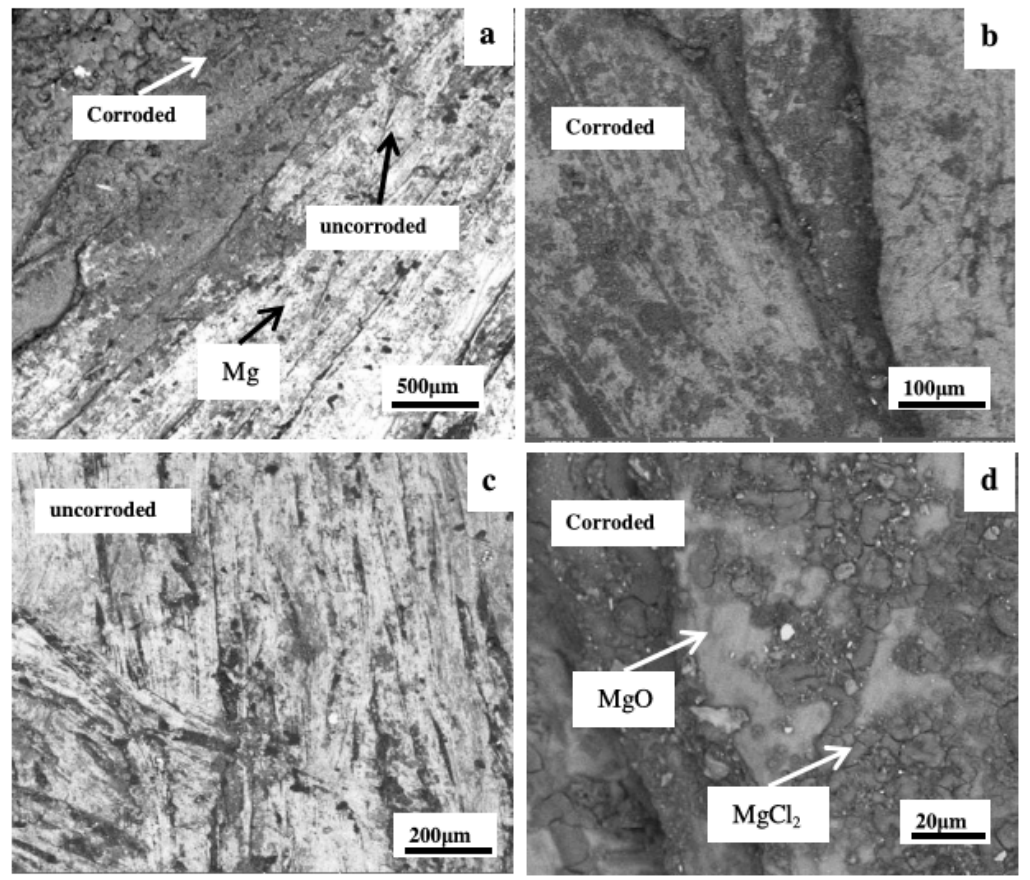

Figure 7 (a-d). BSEI of corroded and un-corroded parts of pure Mg.

\section{Microstructure of pure $\mathrm{Mg}$}

Fig. 7 (a-d) reveals the backscattered electron images (BSEI) of corroded and uncorroded parts of pure $\mathrm{Mg}$ after 270 days of embedment in concrete, with gradually increased magnification of the area of interest, to systematically 
understand the features of the anode. Fig.7(a) shows the junction of the corroded and un-corroded regions of the anode. Three distinct features could be observed in the micrograph, namely, white, grey and spots of darker shade of grey. EDS spot analysis was carried out to deduce the composition of these features. The spectral composition of the white layer was found to be pure $\mathrm{Mg}$, the grey layer consisted of $\mathrm{MgO}$, while point analysis of the dark grey features confirmed the formation of $\mathrm{MgCl}_{2}$ in the corroded region. Fig. 7(b) and 7(d) show the magnified images of the corroded regions, while Fig.7(c) shows the un-corroded region. It could be seen that there are grey regions in the pure $\mathrm{Mg}$, due to the formation of $\mathrm{MgO}$.

Further, Fig. 8 shows the area analysis of $400 \mu \mathrm{m}$ of the corroded parts of pure $\mathrm{Mg}$. The area analysis affirms the findings of EDS spot analysis, showing the presence of $\mathrm{MgCl}_{2}$ and $\mathrm{MgO}$.
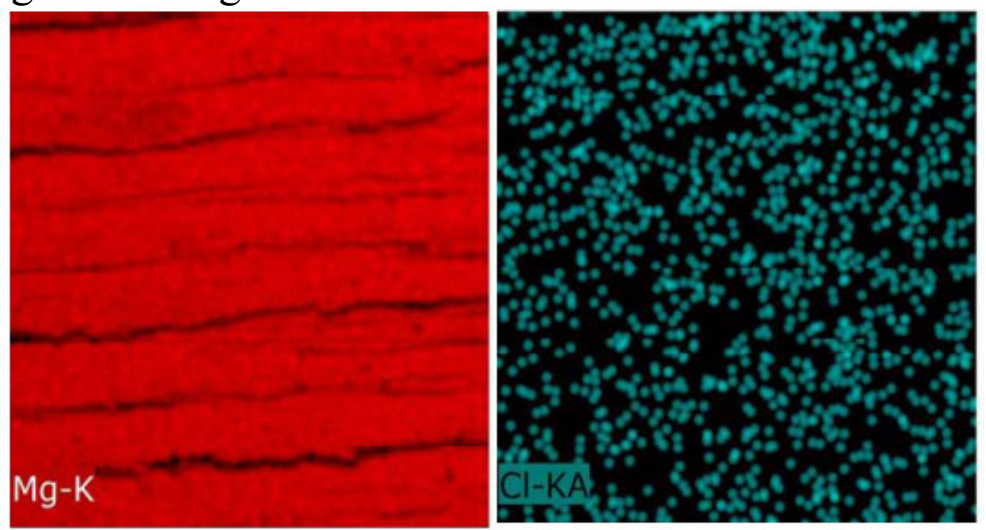

Figure 8. Area analysis of the corroded parts of pure Mg.

\section{Microstructure of AZ91D}

BSEI of the unpolished as-cast alloy revealed that the macroscopically smooth alloy anode actually consisted of ridges or protrusions (Fig.9(a)). The EDS spot analysis revealed that these ridges were composed of $\mathrm{MgO}$, roughly $20 \mu \mathrm{m}$ long. The micro-structure of the polished un-corroded as-cast sample of AZ91D is shown in Fig.9(b). The objective of analyzing the micro-structure of polished sample was to understand the internal structure of the alloy. It consists of a $\mathrm{Mg}$ matrix and inter-metallics, with well-developed primary dendrites distributed along the $\alpha-\mathrm{Mg}$ grain boundaries. The inter-metallics consist of $\mathrm{Mg}_{17} \mathrm{Al}_{12}$ (dark grey) and $\mathrm{Al}_{2} \mathrm{Mg}_{5} \mathrm{Zn}_{2}$ (light grey).

Fig. 9(c) shows the BSEI of the corroded AZ91D alloy, after 270 days of embedment. It consists of irregular oxide nodules (primarily $\mathrm{MgO}$ ) of varying sizes, ranging from 5 to $40 \mu \mathrm{m}$, formed due to the oxidation of the $\alpha-\mathrm{Mg}$ matrix and craters of $\mathrm{MgCl}_{2}$, along with the matrix phase. The oxide nodules were formed preferentially at grain boundaries, while craters of $\mathrm{MgCl}_{2}$ were randomly distributed.

It could be observed that $\mathrm{Mg}_{17} \mathrm{Al}_{12}$ phase acts as a barrier, as well as a potential site for cathodic reaction. Similar observations were reported by Jonsson and Perrson [5]. Further, the area analysis of $400 \mu \mathrm{m}$ (Fig.9. (d)) of the sample shows the findings pictographically above discussed. 

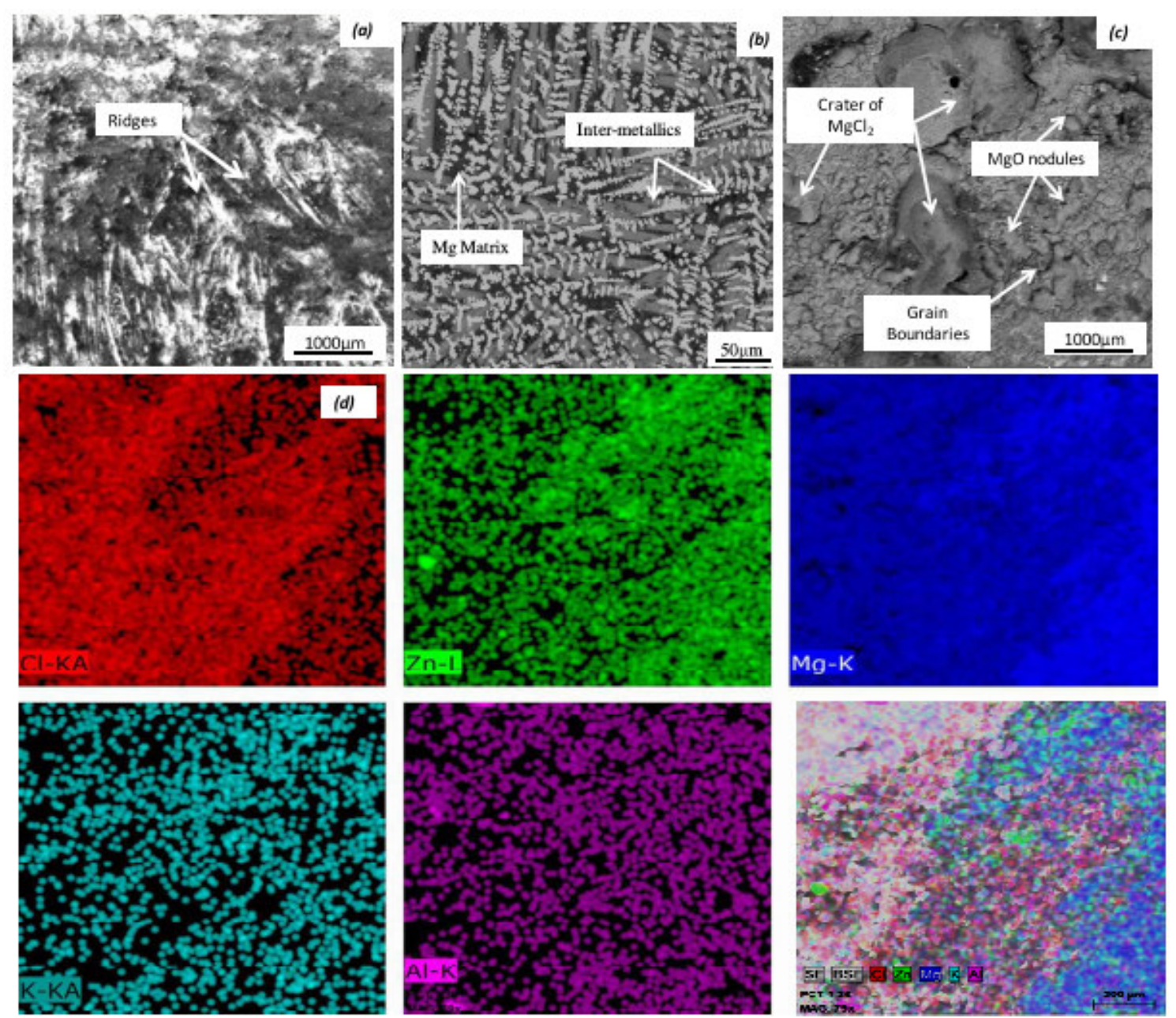

Figure 9. (a) BSEI of unpolished as-cast AZ91D, (b) BSEI of polished as-cast AZ91D, (c) BSEI of the corroded AZ91D alloy after 270 days of embedment and (d) Area analysis of the corroded part of AZ91D.

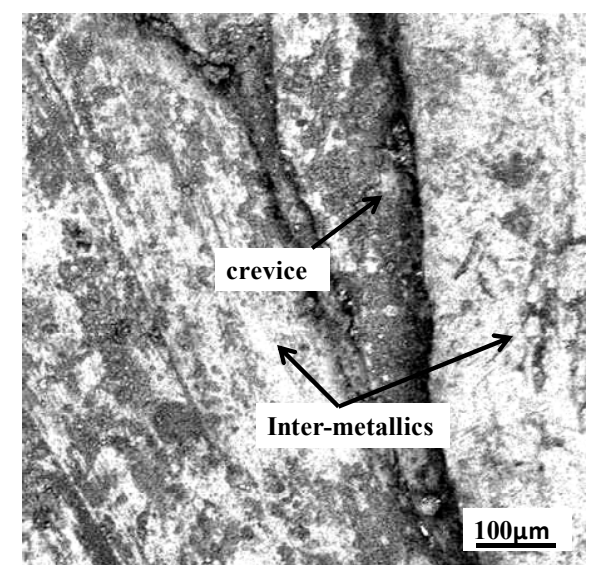

Figure 10. BSEI of corroded AZ91D showing crevices.

From the $100 \mu \mathrm{m}$ BSEI of the corroded AZ91D (Fig.10), it is seen that crevices were formed along the grain boundaries which lead to the following conclusions: 1. The $\mathrm{Mg}$ matrix gets oxidized to $\mathrm{MgO}$ or interacts with chloride forming $\mathrm{MgCl}_{2}$, both of which have higher volumes, leading to the expansion of the matrix and chipping off thereafter. 
2. The electro-chemical potential of the inter-metallics is lower compared to pure $\mathrm{Mg}$, as the chloride ions have preferential interaction with $\mathrm{Mg}$. Thus, the pure Mg matrix acts as "active-sites" for interaction, while inter-metallics are dormant sites. Consequently, the corrosion rate of AZ91D is lower compared to pure $\mathrm{Mg}$.

Thus, it is seen that the process of corrosion of pure $\mathrm{Mg}$ and AZ91D is largely different on a microscopic scale. The reduced rate of corrosion is also mathematically compared in Table 3.

\section{Conclusion}

In the current work, a systematic study was undertaken to investigate the mechanical properties of steel in an electro-chemical contact with pure $\mathrm{Mg}$ and AZ91D anodes, using concrete with $3.5 \% \mathrm{NaCl}$ by weight of cement, and using bare steel in $7.5 \% \mathrm{NaCl}$ dissolved in tap water. The potential of steel embedded in concrete with both the anodes showed a drop in the negative potential w.r.t. $\mathrm{SCE}$, as the days increased. Relative humidity and temperature were found to influence the half-cell potential readings. The yield stress and ultimate tensile stress were found to decrease by approximately $50 \mathrm{MPa}$, while the reduction in percentage elongation was approximately $25 \%$ for reinforcements tied to AZ91D and pure $\mathrm{Mg}$, at the end of 80 days, compared to the fresh steel reinforcement. The mechanical properties of steel coupled with both the anodes showed similar results, but the rate of corrosion of pure $\mathrm{Mg}$ was reportedly slightly higher compared to AZ91D, due to the presence of inter-metallics, as inferred through micro-graphs.

\section{References}

1. Adeniyi AS, Awotunde MA. Corrosion Susceptibility of a $0.35 \%$ C Steel in Seawater Electrolyte Using the Electrochemical Method. Int J Eng Res Africa. 2016;27:20-26.

2. Fan Z, Liu G, Wang Y. Microstructure and mechanical properties of rheodiecast AZ91D magnesium alloy. J Mater Sci. 2006;41-12:3631-3644.

3. Fontana MG. Corrosion engineering. New York: Tata McGraw-Hill Education; 2005.

4. Cao F, Song G-L, Atrens A. Corrosion and Passivation of Magnesium Alloys. Corros Sci. 2016;111:835-845.

5. Jönsson $M$, Persson $D$. The influence of the microstructure on the atmospheric corrosion behaviour of magnesium alloys AZ91D and AM50. Corros Sci. 2010;52-3:1077-1085.

6. Page CL, Tredaway KWJ. Aspects of the electrochemistry of steel in concrete. Nature. 1982;287:109-115.

7. Specification, Indian Standard Drinking Water. IS 10500. Bureau of Indian Standards. 2012.

8. Zander D, Schnatterer C. The influence of manufacturing processes on the microstructure and corrosion of the AZ91D magnesium alloy evaluated using a computational image analysis. Corros Sci. 2015;98:291-303. 